\title{
ALGUNAS REFLEXIONES COMPLEMENTARIAS SOBRE LA CRISIS ECONÓMICA Y LA TEORÍA DEL CICLO
}

\author{
JESÚS HUERTA DE SOTO*
}

Los tres años transcurridos desde el comienzo de la crisis financiera mundial y posterior recesión económica han supuesto la gran oportunidad de la Escuela Austriaca para popularizar su teoría del ciclo económico y su enfoque de análisis dinámico de la realidad social. En mi caso concreto, nunca pude imaginar a principios de 1998, cuando se publicó la primera edición de mi libro Dinero, crédito bancario y ciclos económicos, que doce años después, y gracias, sin duda alguna, a una crisis financiera y recesión económica sin parangón en el mundo desde la Gran Depresión de 1929, y que ningún otro paradigma de nuestra Ciencia pudo predecir y explicar satisfactoriamente, que mi libro sería traducido a catorce idiomas y publicado (hasta ahora) en nueve países, en varias ediciones (dos en Estados Unidos, cuatro en España). Además, durante estos últimos años he sido invitado y he participado en múltiples encuentros, seminarios y conferencias dedicados a presentar mi libro y discutir su contenido y tesis más importantes. En estas ocasiones se han planteado de forma recurrente algunas cuestiones que, si bien ya están en su mayoría cumplidamente discutidas en mi libro, quizás requieran ahora de un cierto tratamiento adicional a la vez sintético y recapitulatorio. Entre ellas mencionaremos en estas «Reflexiones» los siguientes temas:

* Catedrático de Economía Política de la Universidad Rey Juan Carlos. La primera versión de esta nota se escribió en el Señorío de Sarría, el Miércoles Santo 31 de marzo de 2010. Posteriormente fue presentada como «Comunicación» en la Clausura del III Congreso Nacional de Economía de la Escuela Austriaca que tuvo lugar en la Universidad Rey Juan Carlos del 29 de abril de 2010. 


\section{1. - La relación que existe entre la expansión crediticia y el daño medioambiental}

Los teóricos de la denominada «ecología de mercado» (Anderson y Leal, 1993) han demostrado que la mejor manera de preservar el medio ambiente es extendiendo la creatividad empresarial y los principios del mercado libre a todos los recursos naturales, lo que exige su completa privatización y eficaz definición y defensa de sus correspondientes derechos de propiedad. En ausencia de éstos se hace imposible el cálculo económico, impidiéndose la adecuada asignación de los recursos hacia los usos más valorados, y fomentándose todo tipo de comportamientos irresponsables así como el indebido consumo y destrucción de muchos recursos naturales.

Sin embargo, los teóricos de la «ecología de mercado» han pasado por alto otra causa relevante que motiva el mal uso de los recursos naturales: la expansión crediticia que orquestan los bancos centrales e inyectan cíclicamente en el proceso económico a través del sistema de banca privada que actúa privilegiadamente con reserva fraccionaria. En efecto, la expansión artificial de medios fiduciarios genera una fase de burbuja especulativa y euforia financiera («exuberancia irracional») que termina afectando a la economía real, tensionándola indebidamente al aparecer como rentables múltiples proyectos que en realidad no lo son (Huerta de Soto, 2009). Todo ello somete a un stress innecesario todo el entorno natural: se talan árboles que no deberían cortarse, se poluciona la atmósfera, en ensucian ríos, se horadan montes, se fabrica cemento y se extraen minerales, gas y petróleo, etc. para tratar de culminar proyectos demasiado ambiciosos que en realidad los consumidores no están dispuestos a demandar, etc. Al final el mercado terminará imponiendo los criterios de los consumidores y múltiples bienes de capital quedarán ociosos poniéndose de manifiesto que se han producido por error (es decir, con una distribución geográfica y temporal equivocada), pues los empresarios se dejaron engañar por las facilidades crediticias y bajos tipos de interés decretados por las autoridades monetarias. El resultado es un daño ocasionado al entorno natural totalmente innecesario pues no se ha plasmado 
en mejora alguna en el nivel de vida de los consumidores. Por el contrario, éstos se ven empobrecidos al haberse mal invertido el escaso ahorro real de la sociedad en proyectos inviables, demasiado ambiciosos (por ejemplo, un millón de viviendas en España que no encuentran comprador). Por tanto, la expansión crediticia obstaculiza el desarrollo económico sostenible y daña innecesariamente el entorno natural.

La conclusión de este somero análisis es obvia: los amantes de la naturaleza deberían defender un sistema monetario libre, sin banco central y en el que los banqueros privados operaran con un coeficiente de caja del 100 por cien para los depósitos a la vista y equivalentes, utilizando como base monetaria un patrón oro puro. Sólo de esta manera se erradicarían las etapas recurrentes de auge artificial, crisis financiera y recesión económica que tanto daño hacen al entorno económico, al género humano y al proceso de cooperación social.

\section{2. ${ }^{o}$ ¿Es, pues, realmente necesaria la expansión crediticia para impulsar el crecimiento económico?}

Un argumento popular (mantenido y alimentado por no pocos economistas de prestigio como Schumpeter) es el de que la expansión crediticia y los bajos tipos de interés facilitan la introducción de innovaciones tecnológicas y empresariales que impulsan el desarrollo económico. El argumento es deleznable. En una economía de mercado tan importante es proporcionar financiación a un proyecto empresarial solvente y viable, como negárselo a los proyectos alocados e inviables: muchos «empresarios» son como caballos desbocados a los que es preciso restringir sus posibilidades de dilapidar los recursos escasos de la sociedad. El problema es que sólo el mercado es capaz de discriminar unos de otros proyectos, a lo largo de un proceso social en el que, precisamente, es clave el indicador de la cuantía real de los recursos ahorrados y la tasa social de preferencia temporal que ayuda a separar los proyectos que deben financiarse de aquellos a los que aún no ha llegado su momento y, por tanto, deben permanecer «en cartera». Es cierto que toda expansión artificial del crédito y de los medios fiduciarios que lo respaldan produce 
una redistribución de la renta a favor de aquellos que primero reciben las nuevas disponibilidades monetarias y que ello no permite teorizar sobre los efectos netos que el proceso tendrá sobre el ahorro real de la sociedad (dependerá de cómo se compara la preferencia temporal de aquellos que salen ganando con la de aquellos que salen perdiendo). Pero existen indicios más que suficientes para pensar que la inflación desincentiva el ahorro real, aunque sólo sea porque genera un efecto de ilusión de riqueza que impulsa el gasto en bienes de consumo y el consumo de capital. Además, a la larga («ex post») es evidente que sólo puede invertirse lo previamente ahorrado. Pero lo previamente ahorrado puede invertirse bien o mal. La expansión crediticia promueve el despilfarro y la mala inversión de los escasos factores de producción en proyectos de inversión insostenibles y no rentables. Significa ello que el modelo de desarrollo económico basado en la expansión artificial del crédito destruye cíclicamente un elevado volumen de bienes de capital que empobrece significativamente a la sociedad (en comparación con el nivel que podría alcanzarse a largo plazo con un crecimiento sostenible, no forzado por la expansión crediticia y más acorde con los verdaderos deseos de los consumidores en cuanto a sus valoraciones de preferencia temporal).

Y que no se diga que la inflación fiduciaria al menos sirve para dar empleo a lo recursos ociosos, pues el mismo efecto puede lograrse sin mala inversión y despilfarro, flexibilizando los correspondientes mercados laborales y de factores de producción. A la larga, la expansión crediticia genera empleos insostenibles, inversiones equivocadas $\mathrm{y}$, por tanto, un menor crecimiento económico.

\section{3. ${ }^{\circ}$ ¿Es cierto que los bancos causaron la crisis por asumir riesgos desproporcionados en relación con su capital?}

Achacar la crisis al mal proceder de los bancos es confundir los síntomas con las causas. En efecto, los banqueros, durante la etapa de euforia especulativa se limitaron a responder a los incentivos (de tipos de interés reales nulos o negativos y expansión artificial del crédito) creados por los Bancos Centrales. Ahora, 
estas instituciones, en un alarde de hipocresía y manipulación ciudadana, se rasgan las vestiduras, achacan a otros las consecuencias de sus propias políticas erróneas y se esfuerzan en aparecer como «salvadores de la patria» a los que debemos agradecer no haber caído en una depresión aún más profunda. Y ello sin que sea preciso repetir que precisamente durante la etapa del boom la inflación de precios de los activos financieros fue tan elevada que permitió que los banqueros lucieran cuantiosos capitales propios en sus balances que, al menos en apariencia, permitían un elevado apalancamiento y asunción de riesgos sin mayores problemas. Todo ello en un entorno de tipos de interés reales nulos o incluso negativos y de extraordinaria abundancia de liquidez deliberadamente impulsada por los bancos centrales. En estas circunstancias, a nadie debiera sorprender que marginalmente y de manera creciente se financiaran proyectos de inversión de rentabilidad cada vez más reducida y dudosa y de riesgo cada vez más elevado.

\section{4. ${ }^{\circ}$ ¿Entonces el problema de la banca consiste en no haber sabido casar adecuadamente los plazos de las operaciones activas - préstamos-y pasivas -depósitos recibidos-?}

No, el problema es que han operado con reserva fraccionaria, es decir, no han mantenido un coeficiente de caja del 100 por cien en relación con los depósitos a la vista y sus equivalentes. Es decir, el coeficiente de caja del 100 por cien para los depósitos a la vista evita la expansión crediticia y los problemas de liquidez de la banca, pues sólo permite invertir lo previamente ahorrado; y si los inversores se equivocan en el plazo de maduración y sus proyectos son viables pueden pedir nuevos préstamos (basados en ahorro previo y real) para devolver los que van venciendo. Por el contrario, la expansión crediticia que se deriva de la banca con reserva fraccionaria induce una generalizada mala inversión de los recursos que muchos equivocadamente confunden con un erróneo casamiento de plazos, cuando el problema es mucho más profundo: inversiones insostenibles por falta de ahorro real. El problema económico fundamental no lo genera el error en el casamiento de plazos sino la ausencia de 
un coeficiente de caja del 100 por cien, es decir, la banca con reserva fraccionaria.

\section{5. ¿Puede un banco aislado «salvarse de la quema» en caso de expansión crediticia generalizada?}

Un banco individual puede hacerse la ilusión de salir indemne de un proceso de expansión crediticia si (a) piensa que es capaz de prestar marginalmente a los proyectos más rentables y seguros (aquellos que cuando llegue la crisis se vean menos afectados); y (b) cree que al iniciar su expansión crediticia materializada en esos proyectos los demás bancos seguirán la misma política expansiva al menos al mismo ritmo, con lo que no se quedará solo ni perderá reservas.

En la práctica lo indicado en (b) suele acontecer (expansión crediticia generalizada orquestada además por el banco central); pero (a) es muy difícil que suceda y no deja de ser más que una simple ilusión: los nuevos medios fiduciarios (depósitos creados) sólo pueden prestarse a tipos de interés relativamente reducidos y tan sólo pueden colocarse en forma de préstamo en proyectos cada vez más prolongados (es decir, que maduran en un futuro más lejano) y «arriesgados» (inciertos), proyectos que sólo son aparentemente rentables a tipos reducidos, pero que en cuanto éstos suben dejan inmediatamente de ser viables por falta de suficiente ahorro real.

Además, si algún banco tenazmente decide no implicarse en el proceso de expansión crediticia, pierde una creciente cuota de mercado y corre el peligro de convertirse en una exótica irrelevancia, por lo que el efecto corruptor de la banca con reserva fraccionaria sobre todo el sistema bancario es obvio (este argumento ya fue expuesto por Longfield en el siglo XIX). Por otro lado, la práctica bancaria continuamente ha confirmado este fenómeno (por ejemplo diversos presidentes de bancos españoles me han indicado que en la etapa del boom sabían que gran parte de los préstamos inmobiliarios que concedían eran difícilmente viables a largo plazo y muy arriesgados, pero que se vieron «forzados» a participar en múltiples préstamos sindicados y operaciones dudosas por las presiones de los analistas, los 
agentes del mercado y la necesidad de crecer o al menos mantener su cuota de mercado).

\section{6. ${ }^{\circ}$ El ahorro como magnitud «flujo» frente a los saldos de tesorería en forma de depósitos como magnitud «fondo» o «stock»}

El dinero no es un bien de consumo (salvo para el avaro «tío Gilito») ni un factor de producción. Es un tercer tipo de bien: un medio de intercambio comúnmente aceptado. El dinero, además, sólo cumple su función de medio de intercambio como bien presente. Sin embargo, puede ser prestado, en cuyo caso se convierte en un activo financiero para el prestamista al que deja de producir servicios como medio de intercambio.

Es por tanto absurdo decir que el dinero depositado que forma parte de los saldos de tesorería del actor ha sido «ahorrado». El depósito es un saldo de tesorería y, por tanto, una magnitud stock o fondo. El flujo de renta no consumida da lugar al flujo de ahorro que se invierte en activos financieros o directamente en bienes de capital, salvo que alguien decida incrementar indefinidamente sus saldos de tesorería (aumento de la demanda de dinero). Los saldos de tesorería, además, pueden incrementarse no sólo reduciendo el flujo de consumo sino también reduciendo el flujo de inversión (o ambos).

El problema es que con un flujo de ahorro estable y determinado, si alguien decide colocar sus saldos de tesorería en forma de depósitos a la vista en un banco con reserva fraccionaria crece el flujo de préstamos y de inversión sin que haya aumentado el flujo de ahorro real lo cual, precisamente, desencadena el ciclo económico.

Sólo la banca libre con coeficiente de caja del 100 por cien impide la anterior anomalía al hacer imposible para los bancos el asiento

préstamos a depósitos

en el que actualmente fundamentan su principal actividad, pues todo depósito, en consonancia con los principios generales 
del derecho estaría siempre respaldado en caja por el correspondiente saldo de tesorería

$$
\text { caja a depósitos }
$$

\section{7. ${ }^{\circ}$ Es cierto el argumento de Leland Yeager de que es imposible distinguir los depósitos a la vista de los préstamos a muy corto plazo?}

Estando los principios y la teoría claros (que los depósitos a la vista y equivalentes han de estar respaldados en todo momento por un coeficiente de caja del 100 por cien) el mercado encuentra las soluciones más operativas y prácticas en cada momento.

En un sistema bancario ideal, con un coeficiente de caja del 100 por cien, desde luego que los préstamos a corto plazo (1 a 3 meses) serían fácilmente distinguibles de los depósitos a la vista, emprendiendo los agentes implicados las habituales operaciones de casamiento de flujos que tan eficientemente son implementadas en el mercado libre en base a bien probados y ya casi inveterados principios de prudencia.

Los «falsos» préstamos que oculten depósitos serán fácilmente identificables sobre todo teniendo en cuenta que en la frontera del muy corto plazo (de una semana a un mes) la demanda de verdaderos préstamos es muy reducida (si el matching o casamiento de flujos está bien efectuado y salvo en circunstancias muy excepcionales).

En suma, lo importante es si subjetivamente un actor considera que un depósito «a plazo» o un (falso) «préstamo» forma o no parte de sus saldos de tesorería con disponibilidad inmediata. Si es así, nos encontramos ante verdaderos depósitos «a la vista» que exigen un coeficiente de caja del 100 por cien.

\section{8. ¿Cuáles son los escenarios posibles cuando se desencadena una crisis como la actual?}

Básicamente cuatro: 
1. El reinicio de la burbuja, ante dosis masivas de nueva expansión (es casi el peor de los escenarios, pues sólo se logra posponer la depresión a costa de hacerla luego mucho más grave: es lo que sucedió en 2001-2002, cuando se alargó la fase expansiva seis años más pero a costa de una crisis financiera y recesión económica como no se experimentaban en el mundo desde 1929).

2.. El extremo opuesto: la caída en cadena de todos los bancos con reserva fraccionaria y la desaparición del sistema financiero (tragedia que se ha evitado «in extremis» con el salvamento - bail out - de la banca en todo el mundo).

3. «Japonización» de la economía: la intervención gubernamental (fiscal y crediticia) es tan intensa que se bloquean los procesos espontáneos del mercado que tienden a sanear y reestructurar los errores de inversión cometidos en la etapa de la burbuja, con lo cual la economía se mantiene indefinidamente en recesión.

4. ․ Lo más probable: que a «trancas y barrancas» el mercado que es dinámicamente muy eficiente, termine saneando los errores de inversión: las empresas y economías domésticas sanean sus balances reduciendo costes (sobre todo laborales) y devolviendo préstamos. Las empresas que quedan son ya «sanas» y el creciente ahorro permite financiar nuevos proyectos de inversión que sí son sostenibles a largo plazo. El crecimiento del desempleo alcanza su zenit cuando el saneamiento se ha completado, siendo en esa situación prioritario liberalizar al máximo el mercado laboral (contratación, salarios, despidos y negociación colectiva) para reintroducir de nuevo en el circuito productivo (ya sano) a los parados y que éstos se empleen en proyectos viables. Además se precisa la máxima austeridad presupuestaria en el sector público, evitar subir los impuestos y reducir la burocracia y las intervenciones administrativas en la economía.

\section{Actualmente ¿qué medidas podrían tomarse} que fueran en la buena dirección y se aproximaran siquiera muy tímidamente al sistema financiero ideal de una verdadera economía de mercado libre?

El siguiente cuadro permite dar respuesta a esta pregunta: 


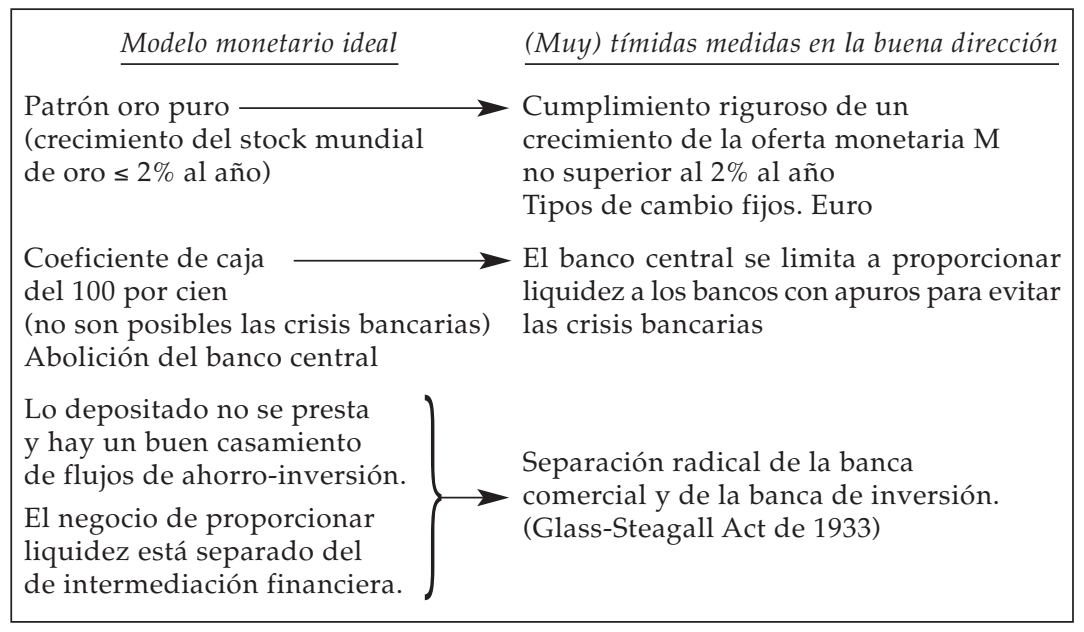

En muchos ámbitos del mercado intervenido que hay que reformar (privatización de calles, inmigración liberal, etc.) es un grave error pensar que hay que eliminar toda regulación mientras no se efectúe la reforma ideal. Todo lo contrario: mientras no se reforme hay que mantener una regulación mínima que simule, en la medida de lo posible, los resultados que tendría el sistema ideal: en el ámbito monetario, patrón oro puro con coeficiente de caja del 100 por cien y sin banco central. No obstante, es preciso repetir una y otra vez que, en vez de intentar torpemente replicar lo que haría el mercado, con parches y paños calientes de muy dudosa efectividad, lo mejor e ineludible es, sin duda alguna, efectuar la reforma definitiva y radical que exige el modelo monetario ideal.

\section{0ํㅡㄹ Conclusión: el desconcierto de teóricos y ciudadanos}

La sociedad está confusa y desconcertada ante la crisis. Su desconexión con los políticos es casi total. La ignorancia y desconcierto de éstos es también espectacular. Pero lo más grave es el vacío teórico de la mayor parte de los propios teóricos de la economía que no aciertan a entender lo que sucede, por qué ha sucedido y lo que puede llegar a suceder. El desprestigio de la economía neoclásica (hipótesis de eficiencia de los mercados, teoría de las 
expectativas racionales, fe en la «autorregulación», principio de racionalidad de los agentes, etc.) es total y se interpreta erróneamente como un fracaso del mercado que justifica más intervención estatal (los keynesianos achacan la crisis al súbito «pánico» financiero y a la falta de demanda agregada que el estado debe completar). Unos y otros fracasan en su comprensión del mercado y por tanto en sus análisis y prescripciones. El vacío teórico en pleno siglo XXI es enorme. Afortunadamente la teoría austriaca del ciclo en general y mi libro Dinero, crédito bancario y ciclos económicos en particular están ahí para llenar ese vacío y acabar con el actual desconcierto.

\section{REFERENCIAS BIBLIOGRÁFICAS}

ANDERson, T.L. y LeAL, D.R. (1993): Ecología de Mercado, Madrid: Unión Editorial.

Huerta De Soto, J. (2009): Dinero, crédito bancario y ciclos económicos, Madrid: Unión Editorial (4.a edición). 